Bangladesh Journal of Anatomy January 2013, Vol. 11 No. 1 pp 11-14

\title{
Significance of Sacral Index in Estimation of Sex in Sacra of Cadavers in Bangladesh
}

\author{
AHM Mostafa Kamal' ${ }^{1}$ Shamim Ara², Md. Mesbahul Hoque ${ }^{3}$, Khadeza Khatun ${ }^{4}$, \\ Kazi Afzalur Rahman ${ }^{5}$
}

\begin{abstract}
Context : The bones of the body are the last to pass away after death, next to enamel of teeth. Hence, in establishing the personal identity with respect to sex, age and stature, medico legal experts, anatomists and anthropologists use the skeletal materials for giving their opinion. Sex-dependent differences have been noted in the pelvic bone anatomy, and so differences exist in male and female sacrum. The aim of this study was to collect data regarding morphometric measurements of maximum length and breadth of sacrum and to find out possible variations of sacral index in different individuals in relation to sex.

Material and Methods: A Cross-sectional, analytical type of study was conducted in the department of Anatomy, Dhaka Medical College, on 172 (one hundred seventy two) adult human dry sacra of unknown sex. The study samples were distributed in male and female sex groups by discriminant function analysis. All the samples were studied morphologically. Sacral length and breadth were measured with the help of digital slide calipers.
\end{abstract}

Result : The mean sacral index in male and female were $97.88 \pm 6.16 \%$ and $112.69 \pm 10.17 \%$ respectively. Female has the greater sacral index than male $(P<0.001)$

Conclusion: Sexing of sacrum, by sacral index method is relevant and significant

Key words : Sacra, sacral Index, discriminant function analysis.

\section{Introduction}

The sacrum is a large, triangular irregular type of bone, situated in the lower part of the vertebral column and at the upper and back part of the pelvic cavity, where it is inserted like a wedge between the two hip bones ${ }^{1}$. Anatomical variations occur frequently in the lower region of the vertebral column, making the sacrum the most variable portion of the vertebra. The variation may be attributed to the dependency of the final sacral morphology to the load-related fusion of the bony structure.

1. Assistant Professor, Department of Anatomy. Dhaka Medical College, Dhaka.

2. Professor and Head, Department of Anatomy, Dhaka Medical College, Dhaka.

3. Assistant Professor, Department of Anatomy, Satkhira Medical College, Satkhira

4. Lecturer, Department of Microbiology . Dhaka Medical College, Dhaka.

5. Assistant Professor, Department of Pharmacology, Sir Salimullah Medical College, Dhaka.

Correspondence : Dr. AHM Mostafa Kamal
Developmental malformations occur as well, ranging from variations in the sacral hiatus to caudal agenesis which gives rise to neurological deficit ${ }^{2}$. The exact identity of sex depends on the number of bones sent for examination. It was by Taylor in his book of medical jurisprudence that the accuracy of estimating the sex from skeletal remains depends upon number of bones available ${ }^{3}$. That is - Skull and Femur $97.35 \%$, Coccyx and Sacrum $97.18 \%$, Pelvis $95 \%$, Skull alone $91.38 \%$, Femur $39.84 \%$, Atlas vertebra $31.18 \%$.

Anatomists, anthropologists and forensic experts judge the sex of the skeletal material by non-metric observations. Thereafter, sexual divergence has been based upon actual measurements in different bones. Though sacrum is often considered to be an important bone while dealing with sex differences in skeletal material, there is paucity of metrical data available for this bone $e^{4}$. Worldwide, various studies have been conducted on the determination of sex 
from variety of human bones i.e. skull, pelvis, long bones, scapula, clavicle, and the bones like metatarsals, metacarpals, phalanges, patella, vertebrae, ribs etc. The most popular statistical model in sex determination is recently developed discriminant function analysis which encouraged many forensic scientists to assess their anthropometric data ${ }^{5}$. Correct classification estimates for the discriminant function range from $66-72 \%{ }^{6}$. The high accuracy of sex assessment $(88.3 \%)$ by the discriminant analysis of the sacral base is a valid method of estimating the sex of skeletal remains from a range of populations. A discriminant function analysis of the three variables of first sacral vertebra produced a prediction accuracy of $92.1 \%{ }^{7}$.

Sex-dependent differences have been noted in the pelvic bone anatomy, and so it follows that differences exist in the male and female sacrum ${ }^{8}$. The sacrum can be used for sexual dimorphism as in anthropological work. The knowledge of sacral index, deiscriminant function analysis and demarking point (DP) is also essential in medicolegal practice for age, sex and race determination of an individual ${ }^{9}$. The well known method for determination of male or female type of sacrum has always ideally been the Sacral Index method ${ }^{10}$.

\section{Materials and Methods:}

A total of 172 (one hundred seventy two) dried completely ossified, grossly normal adult human sacra of unknown sex were assessed. The sacra were collected from Department of Anatomy of Dhaka Medical College, Sir Salimullah Medical College, Shaheed Suhrawardy Medical College, Bangladesh Medical College, Medical College for Women and Hospital, Ibrahim Medical College and H M Somorita Medical College, Dhaka. The study samples were distributed in male and female sex groups by discriminant function analysis. With the help of digital slide calipers different measurements were recorded in millimeters. Measurement of maximum length of sacrum was recorded by the distance from antero-superior margin of promontory to the middle of antero-inferior margin of the last sacral vertebra ${ }^{4}$. Maximum breadth of sacrum was measured by taking two points at the upper part of auricular surface anteriorly ${ }^{10}$. The sacral index (SI) is calculated with formula : Sacral Index= Width of SacrumX100/Height of Sacrum. A comparison of the mean values between sexes was performed using the unpaired Student's't'-test, $p$-value $<0.05$ was considered statistically significant.

\section{Ethical Clearance :}

This study was approved by the Ethical Review Committee of Dhaka Medical College, Dhaka.

\section{Results :}

The mean value of the width was higher in female sacra than that in male sacra and the mean of maximum height was higher in male sacra than that in the female. The mean value of sacral index was higher in female.

Table-I, shows that the mean length of sacrum in male and female was $107.44 \pm 6.95 \mathrm{~mm}$ and $91.65 \pm 7.03 \mathrm{~mm}$ respectively and the mean breadth of sacrum in male and female was $104.63 \pm 6.41$ $\mathrm{mm}$ and $102.77 \pm 6.57 \mathrm{~mm}$ respectively. In case of male, length is greater than breadth and opposite was found in female that was breadth is greater than length $(P<0.001)$.

Table-I

Length and breadth of sacrum in male and female

\begin{tabular}{|c|c|c|c|}
\hline \multirow[b]{2}{*}{ Sex } & \multicolumn{2}{|c|}{ Measurement in $\mathrm{mm}$} & \multirow[b]{2}{*}{$\begin{array}{c}P \\
\text { value }\end{array}$} \\
\hline & $\begin{array}{l}\text { Length }(\mathrm{mm}) \\
\text { Mean } \pm S D\end{array}$ & $\begin{array}{c}\text { Breadth }(\mathrm{mm}) \\
\text { Mean } \pm S D\end{array}$ & \\
\hline $\begin{array}{l}\text { Male } \\
(n=91)\end{array}$ & $\begin{array}{c}107.44 \pm 6.95 \\
(90.13-133.02)\end{array}$ & $\begin{array}{c}104.63 \pm 6.41 \\
(87.80-117.38)\end{array}$ & $<0.001^{\star \star \star}$ \\
\hline $\begin{array}{l}\text { Female } \\
(n=81)\end{array}$ & $\begin{array}{c}91.65 \pm 7.03 \\
(73.17-114.57)\end{array}$ & $\begin{array}{c}102.77 \pm 6.57 \\
(83.08-120.49)\end{array}$ & $<0.001^{* * *}$ \\
\hline$P$ value & $<0.001^{* * *}$ & $<0.01^{* *}$ & \\
\hline
\end{tabular}

Figure in parentheses indicate range. Comparison between length and breadth done by paired Student's ' $t$ ' test and comparison between sex done by unpaired Student's 't' test, ${ }^{* / * * / * *}=$ significant

Table-II, Fig- 1 shows that the mean sacral index in male and female were $97.88 \pm 6.16 \%$ and $112.69 \pm 10.17 \%$ respectively. Female has the greater sacral. The index than male $(P<0.001)$. In male length $(107.44 \pm 6.96 \mathrm{~mm})$ was greater than breadth $(104.63 \pm 41 \mathrm{~mm})$ which reflected lesser sacral index and in female breadth $(99.92 \pm 8.59 \mathrm{~mm})$ was found greater than length $(91.65 \pm 7.04 \mathrm{~mm})$ which reflected greater sacral index $(P<0.001)$. 
Bangladesh J. Anat. 2013; 11(1) : 11-14

Table -II

Mean value of length, breadth and sacral index in male and female

\begin{tabular}{|c|c|c|c|}
\hline \multirow{3}{*}{ Sex } & \multicolumn{3}{|c|}{ Measurement (mm) } \\
\hline & Length & Breadth & Sacral Index (\%) \\
\hline & Mean $\pm S D$ & Mean $\pm S D$ & Mean $\pm S D$ \\
\hline Male & $107.44 \pm 6.96$ & $104.63 \pm 6.41$ & $97.88 \pm 6.16$ \\
\hline$(n=91)$ & $(90.13-133.02)$ & (87.80-117.38) & $(81.47-113.67)$ \\
\hline Female & $91.65 \pm 7.04$ & $102.78 \pm 6.58$ & $112.69 \pm 10.17$ \\
\hline$(n=81)$ & $(73.17-114.57)$ & (83.08-120.49) & (88.33-131.08) \\
\hline$P$ value & $<0.001^{\star \star \star}$ & $<.0 .001^{* * *}$ & $<0.001^{* * *}$ \\
\hline
\end{tabular}

Figure in parenthesis indicate range. Comparison between sex done by unpaired student's 't' test, ${ }^{* / *} /{ }^{* \star *}=$ significant.

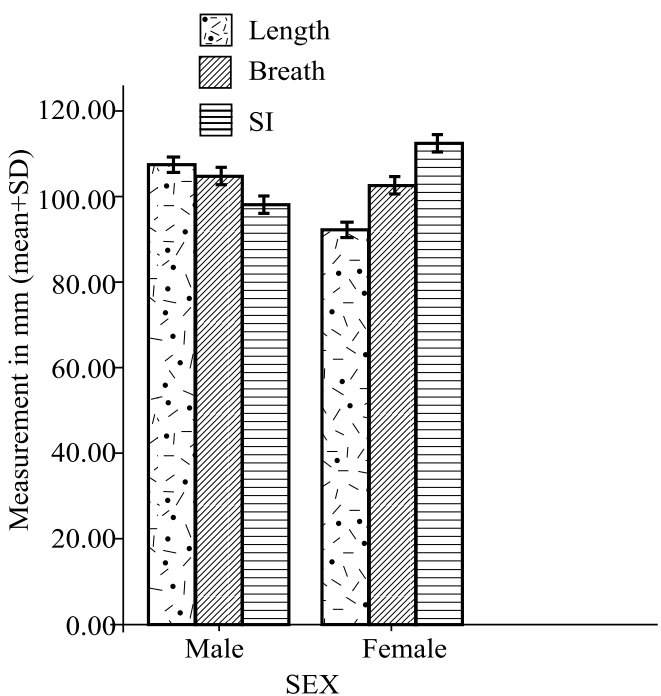

Fig-1: Bar diagram showing values of length, breadth and sacral index (SI) in male and female

\section{Discussion:}

In the present study out of 172 (one hundred and seventy two) sacra the mean length of sacrum in male and female was $107.44 \pm 6.95 \mathrm{~mm}$ and $91.65 \pm 7.03 \mathrm{~mm}$ respectively. Mishra et $\mathrm{al}^{4}$ examined 116 adult human dry sacra ( 74 males and 42 females) of Agra region and showed that mean length was greater in male $(107.53 \mathrm{~mm})$ than female $(90.58 \mathrm{~mm})$, which was similar to the present study. Math ${ }^{3}$ described that ventral straight length in male was $110.10 \mathrm{~mm}$ and that for female was $94.50 \mathrm{~mm}$. Mean length of male sacra was significantly higher than in female which was similar to the present study. The finding of this study was similar to the findings of Arora $^{9}$.

The mean $( \pm S D)$ breadth of sacrum in this study in male and female was $104.63 \pm 6.41 \mathrm{~mm}$ and $102.77 \pm 6.57 \mathrm{~mm}$ respectively. Mean width of sacrum in male was $105.34 \mathrm{~mm}$ and $105.79 \mathrm{~mm}$ in female as described by Mishra et $\mathrm{al}^{4}$. They stated that in female breadth is greater than male. Math ${ }^{3}$ described that width of sacrum in male was 104.20 $\mathrm{mm}$ and that for female $106.30 \mathrm{~mm}$. He also described that sacrum with maximum transverse length measuring above $117.00 \mathrm{~mm}$ is definitely a male and below $86.00 \mathrm{~mm}$ is definitely a female. Arora $^{9}$ examined sacra of Punjab region and showed that maximum breadth of male sacrum was $101.94 \mathrm{~mm}$ and in female was $114.13 \mathrm{~mm}$. The mean breadth of sacrum in male was similar to the values reported by Mishra et al ${ }^{4}$ and Math ${ }^{3}$.

The mean sacral index in male and female were $97.88 \pm 6.16 \%$ and $112.69 \pm 10.17 \%$ respectively. Female has the greater sacral index than male and the difference was statistically highly significant $(<0.001)$. Patel ${ }^{11}$ reported the range of sacral index for males as $90.5-106 \%$ and in case of females $104.8-131 \%$. Mean sacral index for male was $96.25 \%$ and for female was $113.25 \%$ which was similar to present study. According to Math $^{3}$ average value for sacral index in male were $94.24 \%$ and that for females were $113.19 \%$. Mean value of female was significantly higher than male which was also similar to present study. 


\section{Conclusion}

The present study showed that male sacral length was greater than breadth but in female breadth was greater than length. Female has the greater sacral index than male. The present study therefore revealed that for sexing of sacrum sacral index method is relevant and more significant.

\section{References}

1. Newell RLM. Osteology. S. Standring, ed. Gray's Anatomy The Anatomical Basis of Clinical Practice. Paris: Churchill Livingston 2008: 724-28.

2. Mehta S, Joshua D, Auerbach MD. Christopher T, Born MD, Kingsley et al. Sacral fractures. J Am Acad Orthop Surg. 2006; 14(12): 656-65.

3. Math SC. Sexual dimorphism in sacrum. M.S. Rajiv Gandhi University of Health Sciences, Karnataka, Bangalore 2006: 59-69.

4. Mishra SR, Singh PJ, Agrawal AK, Gupta, RN. Identification of sex of sacrum of agra region. J Anat. Soc. India 2003; 52(2): 132-36.
5. Krishan K. Anthropometry in forensic medicine and forensic science-'forensic anthropometry'. The Internet Journal of Forensic Science 2007; 2(1): 1-12.

6. Plochocki JH. Sexual dimorphism of anterior sacral curvature. Journal of Forensic Sciences 2011; 56(1) : 161-64.

7. Benazzi S, Maestri C, Parisini S, Vecchi F, Gruppioni G. SexAssessment from the Sacral Base by Means of Image Processing. Journal of Forensic Sciences 2009; 54(2): 249-54.

8. Cheng JS, Song JK. Anatomy of the Sacrum. Neurosurg Focus 2003; 15(2): 1-9.

9. Arora KA, Gupta P, Mahajan S, Kapoor SS. Significance of sacral index in estimation of sex in sacra of cadavers in Punjab. J Indian Acad Forensic Med 2008; 32(2):104.

10. Baptist M, Sultana F, Farzana F. Sex differences in sacra in the Punjab region. Biomedica. 2008; 24 (23):152-57.

11. Patel MM, Gupta BD, Singel TC. Sexing of sacrum by sacral index and kimura's basewing index. Jiafm 2005; 27 (1): 971-73. 